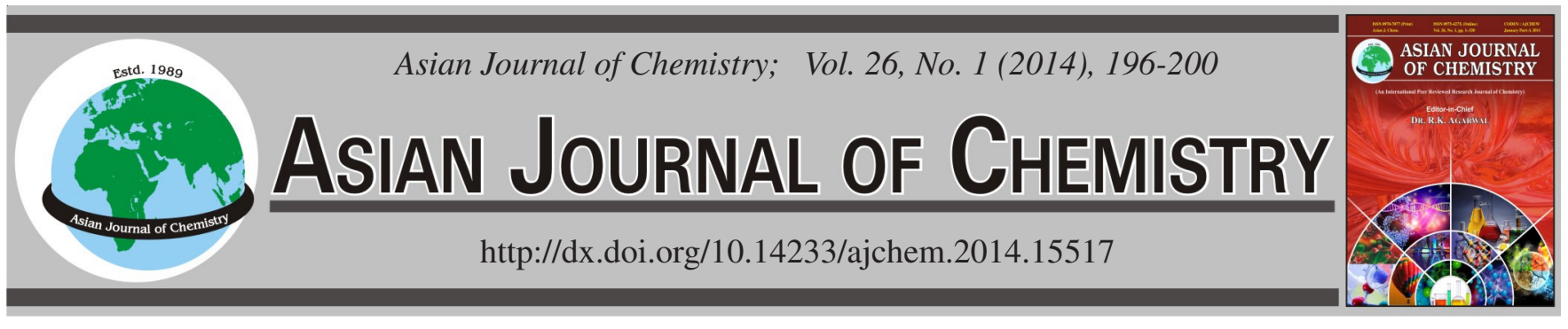

\title{
Synthesis and Characterisation of $\mu$-Oxy-bis[triphenylbismuth(V)] Dicarboxylates and Halo-Carboxylates
}

\author{
Kiran Singhal ${ }^{1, *}$, Subhas Kumar Chaudhary ${ }^{1}$, Vishnu Kumar Sahu $^{2}$ and Prem Raj ${ }^{1}$
}

${ }^{1}$ Department of Chemistry, University of Lucknow, Lucknow-226 007, India

${ }^{2}$ Department of Chemistry, Maharani Lal Kunwari Post Graduate College, Balrampur-271 201, India

*Corresponding author: E-mail: kiran.singhal@gmail.com

\begin{abstract}
Several unknown $\mu$-oxybis[triphenylbismuth]dicarboxylates and $\mu$-oxy-bis[triphenylbismuth]chloro-carboxylates of the general formula $\mathrm{Ph}_{3} \mathrm{Bi}(\mathrm{L})-\mathrm{O}-\mathrm{Bi}(\mathrm{L}) \mathrm{Ph}_{3}$ and $\mathrm{Ph}_{3} \mathrm{Bi}(\mathrm{Cl})-\mathrm{O}-\mathrm{Bi}(\mathrm{L}) \mathrm{Ph}_{3}$, respectively have been synthesised by the metathetical reactions of $\mu$-oxybis[triphenylbismuth]dichloride reactions and silver salts of corresponding carboxylic acids in 1:2 and 1:1 ratio [where $\mathrm{L}=2$-pyrazine carboxylic acid, $p$-methoxy mandelic acid, salicylic acid, benzillic acid and $p$-(trifluoromethyl)mandelic acid)]. The newly synthesized bismuth derivatives have been characterized on the basis of melting point, elemental analysis, IR ${ }^{\mathrm{I}} \mathrm{H}$ and ${ }^{13} \mathrm{C}$ NMR spectra. The molecular weight and conductivity data indicate the monomeric and non electrolytic behaviour in solution.
\end{abstract}

Keywords: $\mu$-Oxybis(triphenylbismuth)dicarboxylates, $\mu$-Oxybis(triphenylbismuth)chlorocarboxylates.

\section{INTRODUCTION}

Despite a voluminous amount of work done on organobismuth $(\mathrm{V})$ compounds $\mathrm{R}_{3} \mathrm{BiX}_{2}(\mathrm{X}=$ halides, pseudohalides, carboxylate, amine, oxime, etc.), these having $\mathrm{Bi}-\mathrm{O}-\mathrm{Bi}$ linkage have not been much studied. Although the synthesis of $\left(\mathrm{R}_{3} \mathrm{Bi}-\right.$ $\left.\mathrm{O}-\mathrm{BiR}_{3}\right) \mathrm{X}_{2} ; \mathrm{X}=$ an anion have been reported by Geol et $a l^{1}$. Further synthesis of biologically patent compounds lacking parallel compounds of antimony having Sb-O-Sb bonds which are analogs of stibogluconate have been founds to possess remarkably anti-leishmaniasis activity like stibogluconate but at the same time they are toxic stiboglluconate is a patent drug but due to toxicity cannot be administered for a longer period.

It is well known that $\mathrm{Bi}-\mathrm{C}$ bond is biodegradable and inorganic bismuth is non-toxic and not retained by the body organs. The lack of published data coupled with our interest on M-O-M compounds and to overcome the problem of acute toxicity associated with antimony compounds, we considered it worthwhile to synthesize $\mathrm{Bi}-\mathrm{O}-\mathrm{Bi}$ compounds in association of carboxylic moieties synthesized some dicarboxylate and halocarboxylate of the general formula $\left(\mathrm{R}_{3} \mathrm{Bi}-\mathrm{O}-\mathrm{BiR}_{3}\right)\left(\mathrm{OCOR}^{1}\right)_{2}$ and $\left(\mathrm{R}_{3} \mathrm{Bi}-\mathrm{O}-\mathrm{BiR}_{3}\right) \mathrm{Cl}\left(\mathrm{OCOR}^{1}\right)$ and characterized them by melting point, elemental analysis and IR and NMR spectra.

\section{EXPERIMENTAL}

Detailed examples of $\mu$-oxy-bis[triphenylbismuth(V)] carboxylate preparation are described below and the conditions for the reaction are summarized in Table-1. Physico-chemical data are given in Tables 1-5.

1:2 Molar ratio reaction of $\left[\left(\mathrm{C}_{6} \mathrm{H}_{5}\right)_{3} \mathrm{BiCl}\right]_{2} \mathrm{O}$ with silver salt of benzilic acid: A solution of $\left[\left(\mathrm{C}_{6} \mathrm{H}_{5}\right)_{3} \mathrm{BiCl}\right]_{2} \mathrm{O}(0.483 \mathrm{~g}$ $0.5 \mathrm{mmol})$ and silver salt of benzilic acid $(0.335 \mathrm{~g} 1 \mathrm{mmol})$ in THF (20 mL) was stirred at room temperature for $24 \mathrm{~h}$. On filtration of heterogeneous solution containing precipitate of silver chloride, a clear solution was obtained which was concentrated in vасио (2-3 mL). After the addition of $n$-hexane $(3 \mathrm{~mL})$ the solution was allowed to stand overnight at $0{ }^{\circ} \mathrm{C}$ affording a white crystalline solid which was recrystallised from a mixture of THF and $n$-hexane (1:3). The compound was characterized as $\mu$-oxy-bis[triphenylbismuth(V) benzilate], m.p. $120^{\circ} \mathrm{C}$, yield: $67 \%$.

In the same manner $1: 1$ molar ratio reaction of $\left[\left(\mathrm{C}_{6} \mathrm{H}_{5}\right)_{3} \mathrm{BiCl}\right]_{2} \mathrm{O}(0.967,1 \mathrm{mmol})$ with silver salt of benzilic acid $(0.335 \mathrm{~g}, 1 \mathrm{mmol})$ in THF $(15 \mathrm{~mL})$ afforded of white crystalline compound characterized as triphenylbismuth(V) benzylate- $\mu$-oxo-triphenylbismuth(V) chloride (m.p. $210^{\circ} \mathrm{C}$, yield: $63 \%$ ).

1:2 Molar ratio reaction of $\left[\left(\mathrm{C}_{6} \mathrm{H}_{5}\right)_{3} \mathrm{BiCl}\right]_{2} \mathrm{O}$ with silver salt of 2-pyrazine carboxylic acid: In an oxygen and moisture free atmosphere a solution of $\left[\left(\mathrm{C}_{6} \mathrm{H}_{5}\right)_{3} \mathrm{BiCl}\right]_{2} \mathrm{O}(0.967 \mathrm{~g}, 1$ mmol) with silver salt of 2-pyrazine carboxylic acid (0.461 g, $2 \mathrm{mmol})$ in dry acetone $(20 \mathrm{~mL})$ was stirred at room temperature for $12 \mathrm{~h}$ followed by refluxion for $3 \mathrm{~h}$. The silver chloride thus formed was filtered off and filtrate on concentration in vacuo 


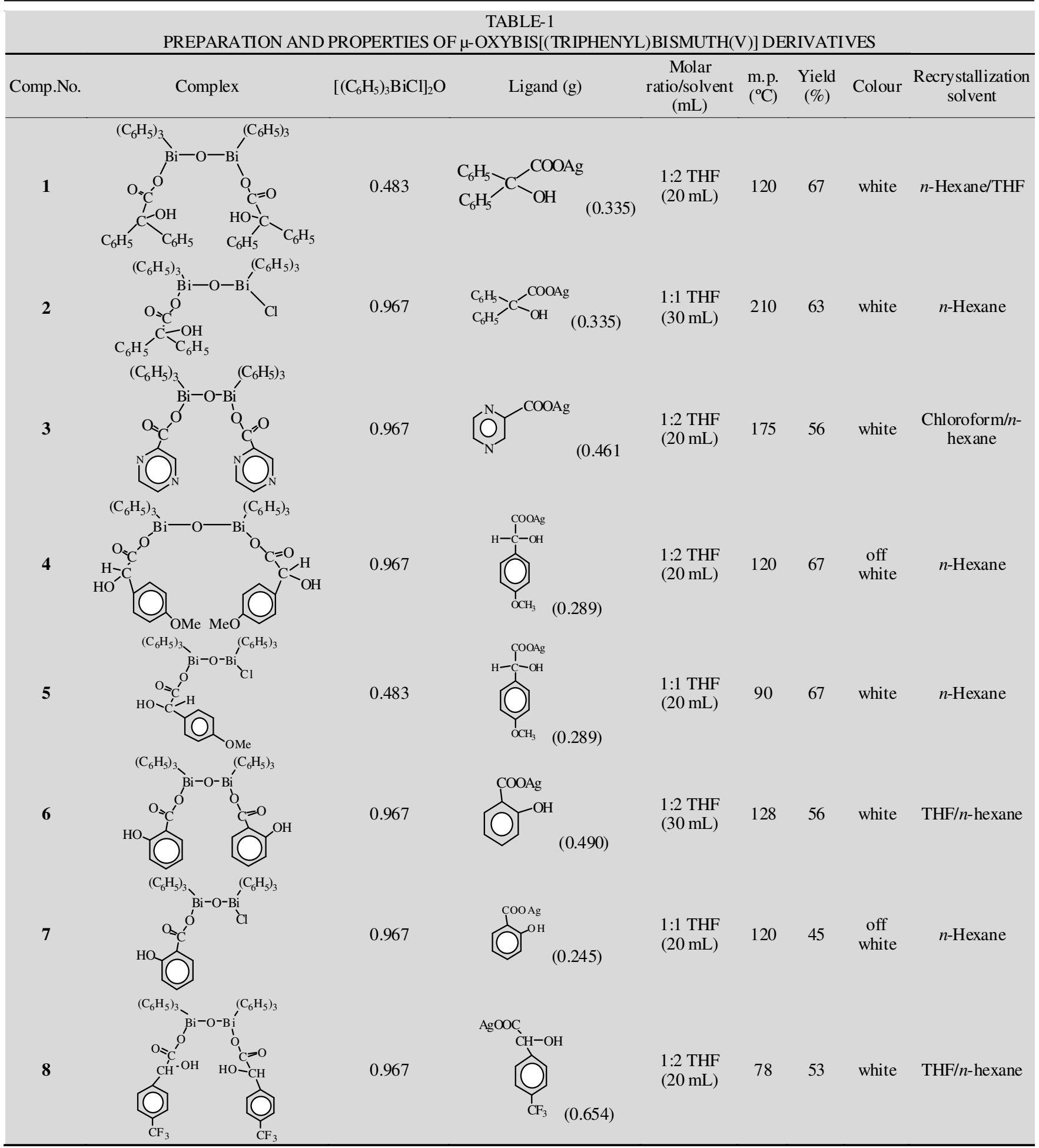

TABLE-2

ELEMENTAL ANALYSIS OF $\mu$-OXYBIS[TRIPHENYLBISMUTH(V)] DERIVATIVES

\begin{tabular}{cccccc}
\multicolumn{7}{c}{ ELEMENTAL ANALYSIS OF $\mu$-OXYBIS[TRIPHENYLBISMUTH(V)] DERIVATIVES } \\
\cline { 3 - 6 } Comp. No. & \multirow{2}{*}{ Emp. Formula } & m.w. & \multicolumn{4}{c}{ Found (calcd.) \% } \\
\cline { 3 - 6 } & & 1351.01 & $57.25(56.90)$ & $3.32(3.88)$ & $\mathrm{N}$ \\
$\mathbf{1}$ & $\mathrm{C}_{64} \mathrm{H}_{52} \mathrm{O}_{7} \mathrm{Bi}_{2}$ & 1159.27 & $51.06(51.80)$ & $3.03(3.56)$ & - \\
$\mathbf{3}$ & $\mathrm{C}_{50} \mathrm{H}_{41} \mathrm{ClO}_{4} \mathrm{Bi}_{2}$ & 1142.76 & $47.92(48.35)$ & $3.68(3.18)$ & $4.17(4.90)$ \\
$\mathbf{4}$ & $\mathrm{C}_{46} \mathrm{H}_{36} \mathrm{~N}_{4} \mathrm{O}_{5} \mathrm{Bi}_{2}$ & 1258.91 & $50.98(51.52)$ & $3.20(3.84)$ & - \\
$\mathbf{5}$ & $\mathrm{C}_{54} \mathrm{H}_{48} \mathrm{O}_{9} \mathrm{Bi}_{2}$ & 1113.20 & $48.08(48.55)$ & $3.15(3.53)$ & - \\
$\mathbf{6}$ & $\mathrm{C}_{45} \mathrm{H}_{39} \mathrm{O}_{5} \mathrm{ClBi}_{2}$ & 1170.81 & $50.87(51.29)$ & $3.10(3.44)$ & - \\
$\mathbf{7}$ & $\mathrm{C}_{50} \mathrm{H}_{40} \mathrm{O}_{7} \mathrm{Bi}_{2}$ & 1069.15 & $48.92(48.31)$ & $3.87(3.30)$ & - \\
$\mathbf{8}$ & $\mathrm{C}_{43} \mathrm{H}_{42} \mathrm{O}_{7} \mathrm{Bi}_{2}$ & 1334.86 & $47.95(48.59)$ & $3.62(3.17)$ & - \\
\hline
\end{tabular}


TABLE-3

CHARACTERISTIC IR ABSORPTION OF $\mu$-OXYBIS[TRIPHENYLBISMUTH(V)] DERIVATIVES

\begin{tabular}{|c|c|c|c|c|c|c|}
\hline \multirow{2}{*}{ Compd. No. } & \multicolumn{3}{|c|}{$\mathrm{v}(\mathrm{OCO})$} & \multirow{2}{*}{$\begin{array}{c}\mathrm{v}(\mathrm{OH}) \\
-\end{array}$} & \multirow{2}{*}{$\frac{\mathrm{v}(\mathrm{Bi}-\mathrm{C})}{(\mathrm{y}-\text { mode })}$} & \multirow{2}{*}{$\frac{v}{(\mathrm{Bi}-\mathrm{O}-\mathrm{Bi})}$} \\
\hline & $\mathrm{V}_{\text {asym }}$ & $\mathrm{V}_{\mathrm{sym}}$ & $\Delta v$ & & & \\
\hline 1 & 1684(s) & $1305(\mathrm{~m})$ & 380 & $3420(w)$ & 459(s) & $640(s)$ \\
\hline 2 & $1677(\mathrm{~s})$ & $1305(w)$ & 378 & $3410(w)$ & $449(\mathrm{~m})$ & 638(s) \\
\hline 3 & $1658(\mathrm{vs})$ & 1335(vs) & 330 & - & $458(\mathrm{~s})$ & $628(s)$ \\
\hline 4 & $1680(s)$ & 1309(vs) & 378 & $3452(w)$ & 459 (s) & 632(s) \\
\hline 5 & $1680(s)$ & $1305(\mathrm{~m})$ & 383 & $3450(\mathrm{~m})$ & $462(\mathrm{~m})$ & 643(s) \\
\hline 6 & $1634(s)$ & $1302(\mathrm{~s})$ & 332 & $3275(\mathrm{~m})$ & $459(\mathrm{~m})$ & $635(\mathrm{vs})$ \\
\hline 7 & $1636(s)$ & $1305(\mathrm{~s})$ & 329 & 3274(m) & $462(s)$ & $645(s)$ \\
\hline 8 & $1685(\mathrm{~s})$ & 1319 & 363 & $3458(w)$ & 454(s) & $627(s)$ \\
\hline
\end{tabular}

TABLE-4

${ }^{1} \mathrm{H}$ NMR SPECTRAL DATA FOR $\mu$-OXYBIS[TRIPHENYLBISMUTH(V)] DERIVATIVES IN $\delta(\mathrm{ppm})$

\begin{tabular}{cccccccc}
\hline Comp. & \multicolumn{3}{c}{ Phenyl ring } & \multicolumn{5}{c}{ Ligand } \\
\hline$($ No. $)$ & $\mathrm{H}_{2}$ & $\mathrm{H}_{3}$ & $\mathrm{H}_{4}$ & $\mathrm{H}_{2}{ }^{2}$ & $\mathrm{H}_{3}{ }^{\prime}$ & $\mathrm{H}_{4}{ }^{\prime}$ & $\mathrm{OCH}_{3}$ \\
\hline 1 & $7.56-7.60(\mathrm{~m})$ & $7.20-7.43(\mathrm{~m})$ & $7.20-7.45(\mathrm{~m})$ & $7.10-7.20(\mathrm{~m})$ & - & - \\
2 & $7.53-7.62(\mathrm{~m})$ & $7.22-7.42(\mathrm{~m})$ & $7.23-7.43(\mathrm{~m})$ & $7.14-7.17(\mathrm{~m})$ & - & - \\
4 & $7.67-7.70(\mathrm{~m})$ & $7.44-7.78(\mathrm{~m})$ & $7.47-7.84(\mathrm{~m})$ & - & $3.85(\mathrm{~s})$ & $5.22(\mathrm{~s})$ & - \\
6 & $7.75-7.83(\mathrm{~m})$ & $7.47-7.75(\mathrm{~m})$ & $7.46-7.75(\mathrm{~m})$ & $6.52-6.59(\mathrm{~m})$ & $7.02-7.09(\mathrm{~m})$ & - & - \\
8 & $7.62-7.71(\mathrm{~m})$ & $7.42-7.75(\mathrm{~m})$ & \multicolumn{7}{c}{$7.41-7.75(\mathrm{~m})$} & - & - & $5.35(\mathrm{~s})$ \\
\hline
\end{tabular}

Where, $\mathrm{m}=$ multiplet, $\mathrm{s}=$ singlet

-

(Phenyl ring)

$(\alpha$-Hydroxy acids $)$

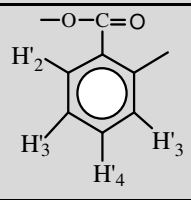

TABLE-5

${ }^{13} \mathrm{C}$ NMR SPECTRAL DATA FOR $\mu$-OXYBIS[TRIPHENYLBISMUTH(V)] DERIVATIVES IN $\delta(\mathrm{ppm})$

\begin{tabular}{ccccccccccc}
\hline Compd. No. & $\mathrm{C}_{1}$ & $\mathrm{C}_{2}$ & $\mathrm{C}_{3}$ & $\mathrm{C}_{4}$ & $\mathrm{C} \alpha$ & $>\mathrm{C}=\mathrm{O}$ & $\mathrm{C}_{1}{ }^{\prime}$ & $\mathrm{C}_{2}{ }^{\prime}$ & $\mathrm{C}_{3}{ }^{\prime}$ & $\mathrm{C}_{4}{ }^{\prime}$ \\
\hline $\mathbf{1}$ & 134.14 & 134.2 & 128.34 & 131.1 & 80.18 & 173.16 & 142.34 & 126.43 & 126.48 & 126.52 \\
$\mathbf{2}$ & 134.45 & 134.23 & 128.12 & 130.26 & 80.72 & 173.04 & 142.66 & 126.97 & 127.28 & 127.33 \\
$\mathbf{3}$ & 135.67 & 134.66 & 128.24 & 130.13 & - & 165.24 & 145.56 & 143.87 & 144.45 & 147.67 \\
$\mathbf{6}$ & 135.45 & 136.56 & 128.32 & 130.34 & - & 173.23 & 141.45 & 130.56 & $116.88 \mathrm{and}$ & 134.76 \\
- & - & - & - & - & - & - & - & $161.58(\mathrm{OH})$ & 118.63 & - \\
$\mathbf{8}$ & 134.45 & 134.35 & 128.57 & 130.53 & 72.45 & 173.24 & 139.78 & 126.52 & 126.38 & 128.14
\end{tabular}<smiles></smiles>

(Phenyl Ring)

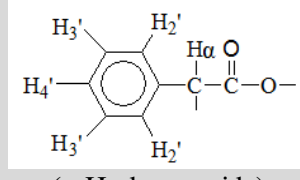

( $\alpha$-Hydroxy acids)

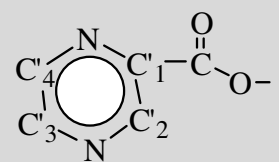

(2-Pyrazine Carboxylate)
(3 $\mathrm{mL}$ ) followed by addition of petroleum ether $\left(60-80{ }^{\circ} \mathrm{C}\right)$ $(3 \mathrm{~mL})$ yielded white crystalline solid. The compound was crystallized from chloroform $/ n$-hexane mixture (1:2) to afford $\mu$-oxy-bis[triphenylbismuth(V) (2-pyrazine carboxylate)] (m.p. $175^{\circ} \mathrm{C}$, yield: $56 \%$ ).

1:2 Molar ratio reaction of $\left[\left(\mathrm{C}_{6} \mathrm{H}_{5}\right)_{3} \mathrm{BiCl}\right]_{2} \mathrm{O}$ with silver salt of salicylic acid: A solution of $\left[\left(\mathrm{C}_{6} \mathrm{H}_{5}\right)_{3} \mathrm{BiCl}\right]_{2} \mathrm{O}(0.967 \mathrm{~g}$, $1 \mathrm{mmol})$ and silver salt of salicylic acid $(0.49 \mathrm{~g}, 2.0 \mathrm{mmol})$ in THF (20 mL) was stirred at room temperature for $24 \mathrm{~h}$. On filtration of heterogenous solution containing precipitate of silver chloride a clear solution was obtained which was concentrated in vасио (2-3 $\mathrm{mL})$. The solution was allowed to stand overnight at $0{ }^{\circ} \mathrm{C}$ affording a white crystalline solid which was recrystallized from a mixture of THF and $n$-hexane (1:3). The compound was characterized as $\mu$-oxy-bis[triphenylbismuth(V) salicylate] (m.p. $128^{\circ} \mathrm{C}$, yield: $56 \%$ ).
In the same manner 1:1 molar ratio reaction of $\left[\left(\mathrm{C}_{6} \mathrm{H}_{5}\right)_{3} \mathrm{BiCl}\right]_{2} \mathrm{O}(0.967 \mathrm{~g}, 1 \mathrm{mmol})$ with silver salt of salicylic acid $(0.245 \mathrm{~g}, 1 \mathrm{mmol})$ in THF $(15 \mathrm{~mL})$ afforded a white crystalline compound characterised as triphenylbismuth $(\mathrm{V})$ salicylate $\mu$-oxobis-triphenylbismuth(V) chloride (m.p. $120^{\circ} \mathrm{C}$, yield: $45 \%$ ).

1:2 Molar ratio reaction of $\left[\left(\mathrm{C}_{6} \mathrm{H}_{5}\right)_{3} \mathrm{BiCl}\right]_{2} \mathrm{O}$ with silver salt of (RS)-p-(trifluoromethyl) mandelic acid: A heterogenous solution of $\left[\left(\mathrm{C}_{6} \mathrm{H}_{5}\right)_{3} \mathrm{BiCl}\right]_{2} \mathrm{O}(0.967,1 \mathrm{mmol})$ and silver salt of (RS)-p-(trifluoromethyl) mandelic acid (0.654 g $2 \mathrm{mmol}$ ) in THF $(15 \mathrm{~mL})$ were stirred for $2 \mathrm{~h}$ at room temperature, the silver chloride thus formed was filtered off. The filtrate on concentration under vacuo (2-3 mL) afforded white solid after addition of pet. ether $\left(60-80^{\circ} \mathrm{C}\right)(2 \mathrm{~mL})$. The solid compound was crystallized from a mixture of THF and $n$-hexane and was characterized as $\mu$-oxy-bis[triphenylbismuth(V) $p$ (trifluoromethyl) mandelate] (m.p. $78^{\circ} \mathrm{C}$, yield: $53 \%$ ). 


\section{RESULTS AND DISCUSSION}

Mono and di-substituted $\mu$-oxy-bis[triphenylbismuth(V)] derivative can conveniently be prepared by the interaction of $\mu$-oxy-bis[triphenylbismuth chloride] $\left(\mathrm{Ph}_{3} \mathrm{BiCl}\right)_{2} \mathrm{O}$, with the silver salt of corresponding carboxylic acid in 1:1 and 1:2 molar ratio.

$$
\begin{array}{cc}
\left(\mathrm{Ph}_{3} \mathrm{BiCl}\right)_{2} \mathrm{O}+\mathrm{AgL} \longrightarrow \mathrm{THF} \\
\left(\mathrm{Ph}_{3} \mathrm{BiCl}\right)_{2} \mathrm{O}+2 \mathrm{AgL} \underset{\mathrm{THF} \text { or Acetone }}{\longrightarrow} \begin{array}{c}
\mathrm{Ph}_{3} \mathrm{Bi}(\mathrm{Cl})-\mathrm{O}-\mathrm{Bi}(\mathrm{L}) \mathrm{Ph}_{3} \\
+\mathrm{AgCl}
\end{array} \mathrm{Ph}_{3} \mathrm{Bi}(\mathrm{L})-\mathrm{O}-\mathrm{Bi}(\mathrm{L}) \mathrm{Ph}_{3} \\
+2 \mathrm{AgCl}
\end{array}
$$

All the reactions proceed smoothly to give almost quantitative yield of the products. The newly synthesized compounds are white crystalline solid except compounds (4 and 7) which are off white solids. Most of the compounds are soluble in common organic solvents. However, unlike antimony derivatives the corresponding bismuth compounds are quite hygroscopic and can be stored only in an inert atmosphere. Melting point of the compounds were taken in sealed tubes and are uncorrected. The molar conductance values of the compounds in acetonitrile $\left(10^{-3} \mathrm{M}\right.$ solutions $)$ were found in the appropriate range (15-22) show their non-conducting behaviour in solution. The molecular weight and van't Hoff factor 'i' determined cryoscopically in nitrobenzene confirmed their monomeric nature.

Infrared spectra: The infrared absorptions for all the $\mu$ oxy-bis[triphenylbismuth(V)] carboxylates were identified and they resemble well with the reported values ${ }^{2}$. The most important band observed for Bi-O-Bi occur in the range $645-627 \mathrm{~cm}^{-1}$ as a strong to very strong band and is in good agreement with published data ${ }^{2-5}$. Only the asymmetric mode is considered here as according to Wing and Challahan ${ }^{6}$ the corresponding $\mathrm{Bi}-\mathrm{O}-\mathrm{Bi}$ mode will occur below $400 \mathrm{~cm}^{-1}$ the limit of the available spectrophotometer. The $\mathrm{Bi}-\mathrm{C}$ stretching frequency corresponding to mass sensitive $y$ - mode recorded in the range 462$449 \mathrm{~cm}^{-1}$ and is in good agreement to those reported earlier ${ }^{7,8}$.

The position of asymmetric and symmetric OCO stretching modes and separation $(\Delta v)$ between them provides a method of assessing carboxylate coordination modes. Deacon and co-workers ${ }^{9}$ point out that this correlation is limited to recognition of complexes with unidentate carboxylates where $\Delta \mathrm{v}_{\text {unidentate }}>\mathrm{v}_{\text {ionic }}$ and complexes with chelating or bridging carboxylates where $\Delta v_{\text {bridging or chelating is often }}\left\langle\Delta v_{\text {ionic }}\left(\Delta v_{\text {ionic }}\right.\right.$ values are in the range $\left.233-164 \mathrm{~cm}^{-1}\right)$. In case of newly synthesized the $\mu$-oxy-bis[(triphenylbismuth(V)] carboxylates asymmetric and symmetric stretching vibration of diagnostic value were identified in comparison with other reported organobismuth carboxylates ${ }^{10-12}$. Asymmetric $\mathrm{v}(\mathrm{OCO})$ stretching modes were assigned in the range $1685-1634 \mathrm{~cm}^{-1}$ as strong band. While symmetric $v(\mathrm{OCO})$ stretching vibration appear in the range $1335-1302 \mathrm{~cm}^{-1}$. The extent of separation between these two bands comes in the range $380-329 \mathrm{~cm}^{-1}$ between the two modes of carboxylate derivatives and suggest the presence of monodentate ester type carboxylate groups imparting a penta coordinate environment around the bismuth atom. The non-conducting monomeric nature and the absence of bands at 1556,1413 and $650 \mathrm{~cm}^{-1}$ due to carboxylate ion $^{8}$ in the IR spectra further rule out the possibility of an ionic structure. The $v(\mathrm{OH})$ for the compounds $(\mathbf{1 - 2}, \mathbf{4 - 8})$ was observed in the range $3458-3274 \mathrm{~cm}^{-1}$ as a weak or medium band.

${ }^{\mathrm{I}} \mathrm{H}$ NMR spectra: ${ }^{\mathrm{I}} \mathrm{H}$ NMR spectra of the representative compounds were recorded on Brucker DRX-300(300MHz FT NMR) spectrometer using $\mathrm{CDCl}_{3}$ as solvent with chemical shifts being reported as $\delta$ (ppm) from tetramethyl silane (TMS) as reference. The integration of the spectra is in good agreement with the expected values in the complex molecules. The proton magnetic resonance spectra of newly synthesized compounds are listed in Table-4.

The ${ }^{1} \mathrm{H}$ NMR spectral pattern for protons of phenyl ring of triphenylbismuth bridged compounds is similar to that observed in reported works ${ }^{3,5,7}$. Because of the presence of phenyl ring in ligand acid, a complex ${ }^{\mathrm{I}} \mathrm{H}$ NMR for newly synthesised $\mu$-oxy-bis[triphenylbismuth(V)] was obtained, but in each case the $\mathrm{O}-\mathrm{H}$ of phenyl ring was distinguished which was most deshielded and appeared in the range $\delta(7.56-7.83)$ ppm as multiplet. In case of compounds $(\mathbf{1 , 6})$ the signal for the $m$ hydrogens of phenyl ring and $\mathrm{O}-\mathrm{H}$ of ligands acids merged in a set of multiplet and appeared in the range $\delta$ (7.207.75) $\mathrm{ppm}$. The $\mathrm{m}$ - and $\mathrm{p}$ - proton of ligand acid in case of salicylate derivative (6) were observed at $\delta(6.52-6.59)$ and $\delta$ (7.02-7.09) ppm, respectively in the form of multiplet. The signal for $\alpha$-hydrogen in case of compounds $\mathbf{( 4 , 8 )}$ was observed in expected range $\delta(5.22-5.35) \mathrm{ppm}$ as singlet. The proton spectrum of $\mu$-oxy-bis[triphenylbismuth $(\mathrm{V}) p$-methoxy mandelate] (4) showed the expected signal at $\delta 3.85 \mathrm{ppm}$ for $\mathrm{OCH}_{3}$ group as singlet.

${ }^{13} \mathrm{C}$ NMR spectra: ${ }^{13} \mathrm{C}$ NMR spectra of representative compounds were recorded on $300 \mathrm{MHz}$ FT NMR (Bruker DRX-300) spectrometer operating at ca. $75 \mathrm{MHz}$ using $\mathrm{CDCl}_{3}$ and DMSO as solvent and reference. The signals for $\mathrm{CDCl}_{3}$ and DMSO appear at 77.0 and 40.0 ppm as triplet and septet, respectively. The chemical shift values for different carbon centres in $\delta(\mathrm{ppm})$ are listed in Table-5.

The chemical shift behaviour of carbon centres of phenyl ring is dependent on the $\mathrm{p}_{\mathrm{ka}}$ values of the carboxylic acids ${ }^{[13]}$. In this way ligand acids having less $\mathrm{p}_{\mathrm{ka}}$ value showed the position of each carbon centres of phenyl ring to be at higher field compared to the acids having higher $\mathrm{p}_{\mathrm{ka}}$ value. The carbon centres of the phenyl ring of compound (1) shift to lower field in comparison to monosubstituted compound (2) due to the decrease in electronegativity of carboxylate group in comparison to chloro group ${ }^{12,13}$ for the same compounds $(1,2)$ the ipso-carbon left significant change where the electron density seems decreased because of replacement of more electronegative chloro group with carboxylate group ${ }^{14}$. The ipso-carbon of the phenyl ring appear in the range $\delta$ (134.14$135.67) \mathrm{ppm}$. Where, as $o-, m$ - and $p$-C of phenyl ring were observed in the range $\delta(134.20-136.56)$ ppm $\delta$ (128.12128.57) ppm and $\delta$ (130.13-131.10) ppm, respectively.

The signals for magnetically non-equivalent carbon centres of ligand acid appeared at different $\delta$-value and the 
signal for carbonyl $(>\mathrm{C}=\mathrm{O})$ carbon was observed in the range $\delta(165.24-173.24) \mathrm{ppm}$ with a shiftment towards lower field in comparision to that of free acid which indicates the participation of carboxylate group in the formation of $\mathrm{Bi}-\mathrm{O}-\mathrm{C}(\mathrm{O})$ bond ${ }^{15,16}$. In case of compound $(\mathbf{1 , 8})$ the chemical shift values for $\alpha$-C appears in the range $\delta(72.45-80.72) \mathrm{ppm}$. These values are at lower field in comparison to free acids showing the deshielding effects at $\alpha$-carbon centres due to the coordination of carboxylate group to bismuth.

Thus on the basis of molecular weight, conductivity, IR and NMR $\left({ }^{1} \mathrm{H}\right.$ and $\left.{ }^{13} \mathrm{C}\right)$ spectral data, the $\mu$-oxy-bis[triphenylbismuth $(\mathrm{V})$ ] derivatives prepared in the present investigation may be assigned a trigonal-bipyramidal structure with a $\mathrm{Bi}-\mathrm{O}-\mathrm{Bi}$ linkage and on each bismuth atom more electronegative groups are situated at apical position (Fig. 1). The similar structure has also been established for other reported $\mu$-oxoderivatives of bismuth.

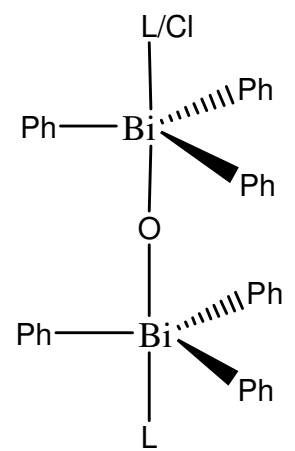

Fig. 1. Where, $\mathrm{L}=\mathrm{OHC}_{6} \mathrm{H}_{4} \mathrm{COO}, \mathrm{Ph}_{2}(\mathrm{OH}) \mathrm{COO}, \mathrm{R}^{\prime} \mathrm{CH}(\mathrm{OH}) \mathrm{COO}\left(\mathrm{R}^{\prime}=p\right.$ $\mathrm{CF}_{3} \mathrm{C}_{6} \mathrm{H}_{4}$ and $p-\mathrm{OCH}_{3} \mathrm{C}_{6} \mathrm{H}_{4}$ ) and 2-pyrazine carboxylate

\section{Conclusion}

$\mu$-Oxybis(triphenylbismuth) dicarboxylates and halocarboxylates having $\mathrm{Bi}-\mathrm{O}-\mathrm{Bi}$ linkage are stable and non-hygro- scopic complexes. They are effective antibacterial and antifungal compounds and expected to display anti-leishmaniasis activity like antimony amalogues stibogluconate.

\section{ACKNOWLEDGEMENTS}

The authors are thankful to Head of Chemistry Department for necessary laboratory facilities and U.G.C., New Delhi for financial assistance vide project No. 37-429/2009(SR).

\section{REFERENCES}

1. R.G. Goel and H.S. Prasad, Can. J. Chem., 48, 2488 (1970).

2. K. Singhal, D.K. Srivastava and P. Raj, Int. J. Sci. Eng. Res., 4, 23 (2013).

3. G.O. Doak, G.G. Long and L.D. Freedman, J. Organom. Chem., 4, 82 (1965).

4. R.G. Goel and D.R. Ridley, J. Organomet. Chem., 182, 207 (1979).

5. P. Raj, A.K. Saxena, K. Singhal and A. Ranjan, Polyhedron, 4, 251 (1985).

6. R.M. Wing and K.P. Callahan, Inorg. Chem., 8, 871 (1969).

7. P. Raj, R. Rastogi, K. Singhal and A.K. Saxena, Polyhedron, 5, 1581 (1986).

8. K. Nakamoto, Infrared and Raman Spectra of Inorganic and. Coordination Compounds, John Wiley \& Sons, Inc. New York, edn. 3, p. 71 (1986).

9. G.B. Deacon, F. Huber and R.J. Phillips, Inorg. Chim. Acta, 104, 41 (1985).

10. M.N. Gibbons, A.J. Blake and D.B. Sowerby, J. Organom. Chem., 543, 217 (1997).

11. P. Raj, S. Agnihotri and K. Singhal, Synth. React. Inorg. Met.-Org. Chem., 32, 569 (2002).

12. A.K. Saxena, A. Ranjan, K. Mishra and P.S. Vonkatamani, Indian J. Chem., 37A, 736 (1998).

13. S.K. Shukla, A. Ranjan and A.K. Saxena, J. Fluorine Chem., 113, 155 (2002).

14. M. Yanaga, T. Miura, K. Endo, H. Nakahara and M. Takeda, Bull. Chem. Soc. Japan, 59, 3085 (1986).

15. J. Holecek, K. Handler, A. Lycka, T.K. Chattopadhyay, B. Majee and A.K. Kumar, Collect. Czech. Chem. Commun., 51, 1100 (1986).

16. S. Ali, F. Ahmad, M. Mazhar, A. Munir and M.T. Masood, Synth. React. Inorg. Met. Org. Chem., 32, 357 (2002). 